\title{
Field and laboratory approaches for determining sodicity effects on saturated soil hydraulic conductivity
}

\author{
V. Bagarello ${ }^{\mathrm{a}}$, M. Iovino ${ }^{\mathrm{a}}$, E. Palazzolo ${ }^{\mathrm{b}}$, M. Panno ${ }^{\mathrm{b}}$, W.D. Reynolds ${ }^{\mathrm{c}, *}$ \\ ${ }^{a}$ Dipartimento di Ingegneria e Tecnologie Agro-Forestali, Sezione Idraulica, Università degli Studi di Palermo, \\ Viale delle Scienze, 90128, Palermo, Italy \\ ${ }^{\mathrm{b}}$ Dipartimento di Ingegneria e Tecnologie Agro-Forestali, Sezione Chimica, Università degli Studi di Palermo, \\ Viale delle Scienze, 90128, Palermo, Italy \\ ${ }^{\mathrm{c}}$ Greenhouse and Processing Crops Research Centre, Agriculture and Agri-Food Canada 2585 County Road 20, \\ Harrow, Ontario, Canada NOR 1G0
}

Received 9 July 2004; received in revised form 26 November 2004; accepted 6 January 2005

Available online 19 February 2005

\begin{abstract}
Dilution of high-sodicity soil water by low-sodicity rainfall or irrigation water can cause declining soil hydraulic conductivity $(K)$ by inducing swelling, aggregate slaking and clay particle dispersion. Investigations of sodicity-induced reduction in $K$ are generally restricted to repacked laboratory cores of air-dried and sieved soil that are saturated and equilibrated with sodic solution before tests are conducted. This approach may not yield a complete picture of sodicity effects in the field, however, because of loss of antecedent soil structure, small sample size, detachment of the sample from the soil profile, reliance on chemical equilibrium, and differing time scales between laboratory and field processes. The objectives of this study were to: (i) compare the electrical conductivity (EC), exchangeable sodium percentage (ESP), and sodium adsorption ratio (SAR) in laboratory cores of intact field soil that had, or had not, undergone prior saturation and equilibration with sodic solution; (ii) compare the pressure infiltrometer (PI) field method with the intact laboratory soil core (SC) method for assessing sodicity effects on saturated soil hydraulic conductivity; and (iii) characterize hydraulic conductivity reduction in a salt-affected sandy loam soil and a salt-affected clay soil in Sicily as a result of diluting high-sodicity soil water with low-sodicity water.

In terms of EC, ESP and SAR, quasi-equilibrium between soil and infiltrating solution was attainable in $0.08 \mathrm{~m}$ diameter by $0.05 \mathrm{~m}$ long laboratory cores of intact clay soil, regardless of whether or not the cores were previously saturated and equilibrated with solutions of $\mathrm{SAR}=0$ or 30 . In the sandy loam soil, the PI and SC methods produced statistically equivalent linear reductions in $K$ as a result of diluting increasingly sodic soil water (SAR=0,10,20,30) with deionised water. In the clay soil, the PI method produced no significant correlation between initial soil water SAR and $K$ reduction, while the SC method produced a significant log-linear decline in $K$ with increasing soil water SAR. Sodicity-induced reductions in $K$ ranged from 3$8 \%$ (initial soil water $\mathrm{SAR}=0$ ) to $85-94 \%$ (initial soil water $\mathrm{SAR}=30$ ) in the sandy loam, and from $9-13 \%$ (initial soil water $\mathrm{SAR}=0$ ) to $42-98 \%$ (initial soil water $\mathrm{SAR}=30$ ) in the clay. The reductions in $K$ were caused by aggregate slaking and partial blocking of soil pores by dispersed clay particles, as evidenced by the appearance of suspended clay in the SC effluent during
\end{abstract}

\footnotetext{
* Corresponding author. Tel.: +1 519738 2251x472; fax: +1 5197382929.

E-mail address: reynoldsd@agr.gc.ca (W.D. Reynolds).
} 
infiltration of deionised water. As a result, maintenance of $K$ in these two salt-affected soils will likely require procedures to prevent or control the build-up of sodicity.

(c) 2005 Elsevier B.V. All rights reserved.

Keywords: Saturated hydraulic conductivity; Pressure infiltrometer; Soil core; Sodicity; Aggregate slaking; Clay particle dispersion

\section{Introduction}

Irrigated areas in arid and semi-arid regions of the world often experience declining soil quality as a result of excessive exchangeable sodium content or "sodicity." Sodium sorption-desorption in response to changing cationic strength and composition of the soil solution can induce slaking of aggregates and swelling/dispersion of clay particles. This can in turn decrease soil hydraulic conductivity through the reduction of soil structure and the plugging of soil pores by dispersed clay particles (Abu-Sharar et al., 1987; Yousaf et al., 1987; So and Aylmore, 1993). The slaking-dispersion process can be greatly enhanced when the cationic concentration of the antecedent soil pore water is diluted by infiltrating rainfall and/or low-sodium irrigation water (Frenkel et al., 1978; Crescimanno et al., 1995). In addition, sodium-induced slaking and clay dispersion can be particularly destructive at the soil surface as it may cause the formation of a virtually impermeable surface crust that both impedes water entry into the soil (Agassi et al., 1985; Shainberg et al., 1992) and impairs seedling emergence (Hausenbuiller, 1978). Surface crusting and reduced root-zone soil hydraulic conductivity associated with sodicity can also jeopardize irrigated agriculture by causing increased runoff and erosion, decreased plant-available water and aeration, and increased salinisation through reduced internal drainage (e.g., Bohn et al., 1979). Control of soil sodicity is therefore essential for the long-term sustainability and productivity of irrigated agriculture.

Many studies have been conducted over more than five decades on the effects of sodium on soil hydraulic conductivity (e.g., Sumner, 1993). Most of these studies are restricted, however, to laboratory investigations using air-dried, sieved soils that are repacked into cylinders (cores). In addition, the repacked samples are usually saturated and chemically equilibrated with the sodic test solutions prior to the hydraulic conductivity measurements. These approaches are chosen partly for convenience, partly to achieve maximum sodicity effects (i.e., worst case scenarios), and partly because of a lack of appropriate and practical alternative technologies. Concern has been expressed, however, that repacked and chemically equilibrated laboratory cores may not give a complete picture of sodicity effects in the field because of the loss of antecedent soil structure, small sample size, detachment of the samples from the soil profile, reliance on chemical equilibrium which almost never occurs in the field, and greatly different time scales between laboratory procedures and field processes (Minhas et al., 1994). There has consequently been a long-term desire to complement the traditional approach with alternative methods which more closely emulate the conditions, time scales and processes in the field.

One alternative laboratory approach is to use intact (undisturbed) cores of field-moist soil, rather than repacked soil that has been air-dried and sieved. Intact cores preserve much of the original soil structure, and maintaining field-moist conditions (as opposed to airdrying) may prevent unrealistic alteration of soil physio-chemical conditions, such as drying-induced generation of hydrophobicity and/or formation of oxides and precipitates. In addition, direct leaching of intact soil cores that are initially field-moist may produce flow patterns and degrees of soil-solution equilibrium that are more representative of field processes than sieved and repacked samples that have undergone a prior stage of saturation and equilibration. Although it is well known that flow patterns and equilibration time can influence the soil's hydraulic response to changes in water quality (e.g., Ben-Hur et al., 1998; Moutier et al., 1998; Mamedov et al., 2002), little work in this area has been conducted, especially on intact soil cores which are initially field-moist.

Another approach to determining sodicity effects on soil hydraulic conductivity is to conduct measurements directly in the field using ponded infiltration 
through inserted rings. Advantages of this method are that it provides a flow regime and time scale that are reasonably compatible with natural rainfall or irrigation, especially in regions such as the Mediterranean where high-intensity rain storms and flood irrigation methods are common. Ponded infiltration from inserted rings also does not destroy the antecedent soil structure or change the initial soil moisture conditions, it allows the sampled soil volume to remain physically and hydraulically connected to the rest of the soil profile, and infiltration within the confines of the ring is effectively vertical, as occurs in the field and in soil cores. A potentially suitable method for conducting this type of measurement is the single-ring pressure infiltrometer technique (Reynolds and Elrick, 1990, 2002; Reynolds, 1993). The method is simple and rapid, its self-contained reservoir allows convenient change in infiltrating solution sodicity, and it can provide in situ determinations of the fieldsaturated hydraulic conductivity at the soil surface. Although the pressure infiltrometer method has been available for some time, it has not yet been tested for its applicability to sodicity issues, nor has it been compared to laboratory soil core methods for evaluating sodicity effects on hydraulic conductivity.

The objectives of this study were to (i) compare soil and water quality in laboratory cores of intact field soil that had, or had not, undergone prior saturation and equilibration with sodic solution; (ii) compare the pressure infiltrometer field method with the intact laboratory soil core method for assessing sodicity effects on saturated soil hydraulic conductivity; and (iii) characterize the reduction in saturated hydraulic conductivity for two salt-affected soils in Sicily as a result of diluting high-sodicity soil water with low-sodicity water. Soil and water quality were measured in terms of the electrical conductivity (EC) of the soil solution, the exchangeable sodium percentage (ESP) of the soil exchange complex, the sodium adsorption ratio (SAR) of the influent solutions and soil solutions, and the concentration of suspended clay in soil core effluent. The EC $\left(\mathrm{dS} \mathrm{m}^{-1}\right)$ provided an estimate of the soluble salt content or "salinity" of the soil solution. The ESP (\%) gave the proportion of the soil cation exchange capacity (CEC) occupied by sodium $(\mathrm{Na})$, where $\mathrm{ESP}=[(\mathrm{Na}) /$ $\mathrm{CEC}] \times 100$ and $\mathrm{Na}$ and $\mathrm{CEC}$ are measured in $\mathrm{cmol}$ $\mathrm{kg}^{-1}$ of soil. The SAR was used to estimate the relative "sodium status" of the influent solutions and soil solutions, where $\mathrm{SAR}=(\mathrm{Na}) /[(\mathrm{Ca}+\mathrm{Mg}) / 2]^{1 / 2}$ and $\mathrm{Na}, \mathrm{Ca}$ and $\mathrm{Mg}$ are the concentrations $\left(\mathrm{cmol} \mathrm{kg}^{-1}\right.$ solution) of dissolved sodium, calcium and magnesium, respectively. The concentration of suspended clay in the soil core effluent $\left(\mathrm{g}_{\text {clay }} \mathrm{L}^{-1}\right.$ ) provided a measure of the degree of aggregate slaking and clay particle dispersion.

\section{Materials and methods}

\subsection{Field sites}

The field sites were situated on two common soil types (sandy loam, clay) in two irrigated areas of semi-arid western Sicily located near Palermo and Sparacia (Fig. 1). Table 1 gives the name and location of the field sites, the soil taxonomy and texture (FAO, 1998; USDA, 1998), and various chemical parameters related to salinity and sodicity. As can be seen from Table 1, both soils are salt-affected (ESP $\geq 10 \%)$ and may consequently be susceptible to sodicity-induced declines in hydraulic conductivity as a result of rainfall and/or application of low sodium irrigation water. For the sandy loam soil (Palermo), measurements were taken within a $150-\mathrm{m}^{2}$ flat area supporting a citrus orchard; and for the clay soil (Sparacia), measurements were taken within a $700-\mathrm{m}^{2}$ bare field on a uniform $16 \%$ slope. The sandy loam soil had gravel content of $16.4 \%$ by weight, while the clay soil had negligible gravel content.

\subsection{Intact soil core measurements}

\subsubsection{Sodic solution equilibration procedure}

Only the clay soil was considered, as chemical equilibration is generally more difficult to achieve with finer textured soils than coarser textured soils. Undisturbed soil cores (SCs) were collected at 40 randomly chosen locations at the Sparacia site by gently hand-hammering stainless steel cylinders (inside diameter, $D=0.08 \mathrm{~m}$; height, $h=0.05 \mathrm{~m}$ ) into the surface horizon of the soil. The cores were collected in 2 successive days with no intervening rain or irrigation to minimize differences in initial soil water content. The cores were wrapped in plastic immediately after collection to prevent evaporative 


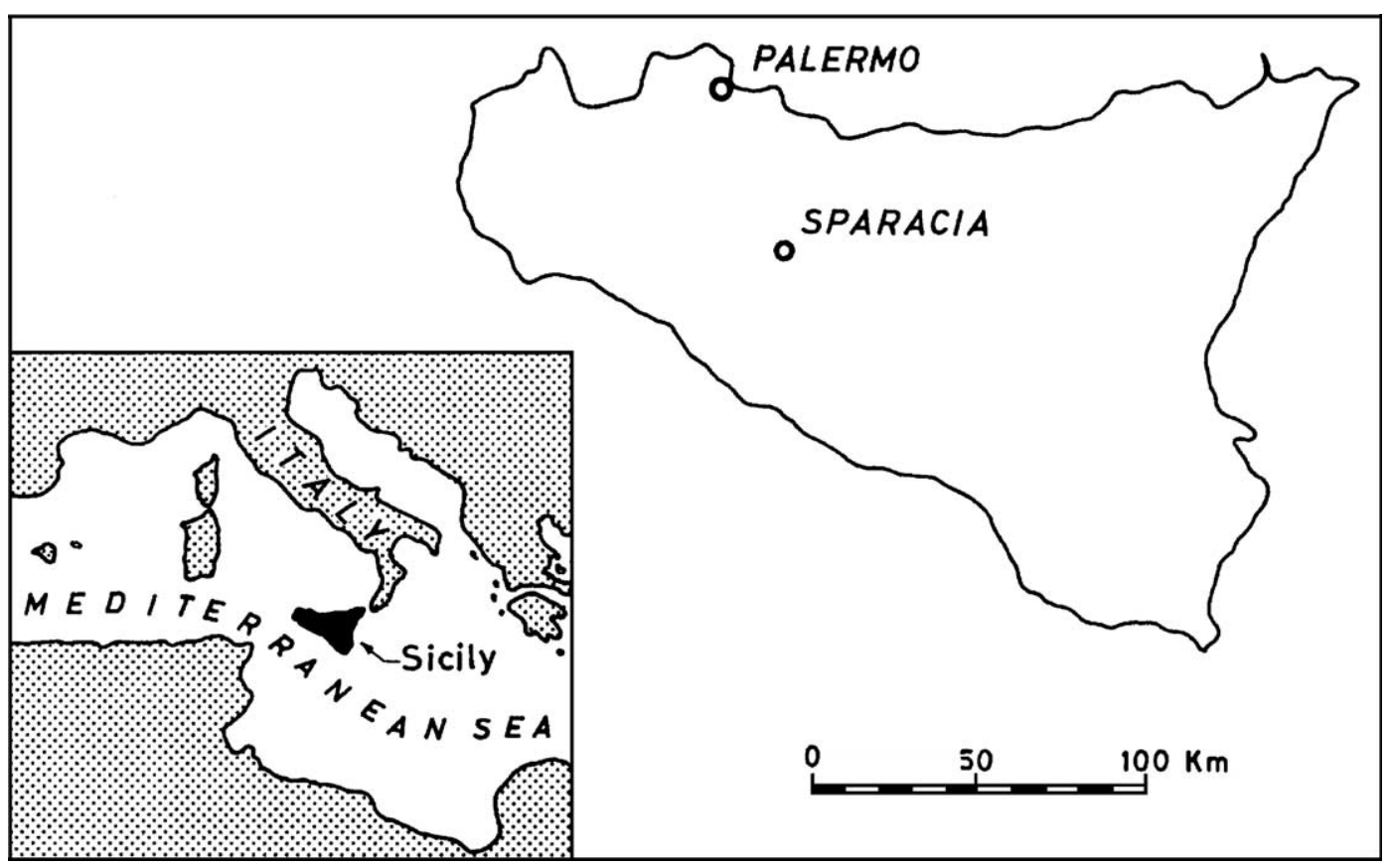

Fig. 1. Field site locations.

water loss, and then stored at $4{ }^{\circ} \mathrm{C}$ to minimize chemical and biological changes before analysis.

Two equilibration procedures were considered: (i) initial saturation with sodic solution using slow upward wetting over several days, then downward infiltration of the sodic solution (IS); and (ii) downward infiltration of sodic solution with no initial saturation phase (NIS). For IS equilibration, the soil cores (sample size, $n=20$ ) were saturated from the bottom with the sodic solution by raising the solution level in four steps over a total time period of $96 \mathrm{~h}$. Once this was completed, downward infiltration with the same sodic solution was initiated. For NIS equilibration, the soil cores $(n=20)$ were not saturated with the sodic solution before initiating downward infiltration. Two solutions were used, one with $\mathrm{SAR}=0$ representing non-sodic water, and one with $\mathrm{SAR}=30$ representing highly sodic water. Both solutions had a fixed cationic concentration of 10

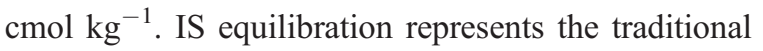
approach to sodicity investigations where complete equilibration between soil and test solution is attempted. NIS equilibration, on the other hand, is more representative of actual field conditions where the

Table 1

Selected field site information

\begin{tabular}{|c|c|c|c|c|c|c|c|c|c|}
\hline \multirow[t]{2}{*}{ Field site name and location } & \multirow[t]{2}{*}{$\begin{array}{l}\text { FAO soil name } \\
\text { and soil type }\end{array}$} & $\begin{array}{l}\text { Clay } \\
(<2 \mu \mathrm{m}) \\
\end{array}$ & $\begin{array}{l}\text { Silt } \\
(2-50 \mu \mathrm{m})\end{array}$ & $\begin{array}{l}\text { Sand } \\
(50-2000 \mu \mathrm{m})\end{array}$ & \multirow[t]{2}{*}{$\mathrm{pH}$} & \multirow[t]{2}{*}{$\begin{array}{l}\mathrm{EC} \\
\left(\mathrm{dS} \mathrm{m} \mathrm{m}^{-1}\right)\end{array}$} & \multirow[t]{2}{*}{ SAR } & \multirow[t]{2}{*}{$\begin{array}{l}\text { CEC } \\
\left(\mathrm{cmol} \mathrm{kg}^{-1}\right)\end{array}$} & \multirow[t]{2}{*}{$\begin{array}{l}\text { ESP } \\
(\%)\end{array}$} \\
\hline & & \multicolumn{3}{|l|}{$\%$ by weight } & & & & & \\
\hline $\begin{array}{l}\text { Palermo } 38^{\circ} 6^{\prime} 32.75^{\prime \prime} \mathrm{N} \\
12^{\circ} 81^{\prime} 9.93^{\prime \prime} \mathrm{E}\end{array}$ & $\begin{array}{l}\text { Rubic Lixisol }{ }^{\mathrm{a}} \text {, } \\
\text { sandy loam }\end{array}$ & $17.7(3.4)^{\mathrm{b}}$ & $25.3(3.2)$ & $57.0(1.8)$ & 7.8 & 0.48 & 0.99 & 25.31 & 10.2 \\
\hline $\begin{array}{c}\text { Sparacia } 37^{\circ} 38^{\prime} 12.48^{\prime \prime} \mathrm{N}, \\
13^{\circ} 45^{\prime} 57.71^{\prime \prime} \mathrm{E}\end{array}$ & $\begin{array}{l}\text { Eutric Vertisol }{ }^{\mathrm{c}} \text {, } \\
\text { clay }\end{array}$ & $62.1(5.4)$ & $21.8(4.0)$ & $16.1(3.7)$ & 6.7 & 0.17 & 1.90 & 44.70 & 14.5 \\
\hline
\end{tabular}

\footnotetext{
${ }^{\text {a }}$ USDA classification: Typic Rhodoxeralf.

${ }^{\mathrm{b}}$ Values in parenthesis are coefficient of variation ( $\left.\%\right)$ ( $n=9$ for the sandy loam, $n=30$ for the clay).

${ }^{c}$ USDA classification: Vertic Xerochrept.
} 
degree of equilibration depends on the rate, patterns and duration of flow.

Downward infiltration was conducted in two stages. Stage 1 involved infiltration under a constant ponded head of 10-15 mm until approximately 15 pore volumes of "sodic" solution had infiltrated all 40 cores (i.e., 20 "IS" cores and 20 "NIS" cores). At the end of stage 1 infiltration, 16 of the soil cores (4 replicate cores for each combination of equilibration procedure and SAR level, i.e., IS using $\mathrm{SAR}=0$ or 30 and NIS using $\mathrm{SAR}=0$ or 30 ) were destructively sampled to determine the EC, ESP and SAR levels (Ministero delle Politiche Agricole e Forestali, 2000). The remaining 24 cores (6 replicate cores for each combination of equilibration procedure and SAR level) were left intact and subjected to stage 2 infiltration, which consisted of displacing the sodic solution from stage 1 by infiltrating an additional 15 pore volumes of deionised water under a constant ponded head of $10-15 \mathrm{~mm}$. The 24 cores were then destructively sampled to determine the EC, ESP and SAR levels at the end of stage 2 infiltration.

\subsubsection{Sodicity effects on hydraulic conductivity}

Intact, field-moist soil cores ( $D=0.08 \mathrm{~m}, h=0.05 \mathrm{~m})$ were collected from the soil surface at 9 random locations at the sandy loam site and 11 random locations at the clay site, using the same collection and storage procedures as for the equilibration experiments. Any possible crusted/smeared/compacted surface layers were scraped off before the cores were collected. The soil cores were initially saturated from the bottom with stage 1 infiltrating solution by raising the solution level in four steps over a 96-h time period. Stage 1 infiltration consisted of infiltrating approximately 15 soil core pore volumes of sodic water with $\mathrm{SAR}=0,10,20$, or 30 (cationic strength held constant at $10 \mathrm{cmol} \mathrm{kg}^{-1}$ ) under a constant ponded head of 10-15 mm. Stage 2 infiltration consisted of infiltrating a further 15 pore volumes of deionised water, also under a constant ponded head of 10-15 mm. The stage 1 SAR levels (i.e., $0,10,20,30$ ) were chosen to produce varying potential for sodicity-induced reduction in hydraulic conductivity, ranging from virtually zero potential $(\mathrm{SAR}=0)$ to high potential $(\mathrm{SAR}=30)$ (Rhoades and Loveday, 1990, Fig. 36-4).
Measurements included determination of the suspended clay content in the core effluent during stage 2 infiltration (deionised water); and calculation of the time required to achieve steady flow, $t_{\mathrm{s}}[\mathrm{T}]$, and saturated hydraulic conductivity, $K_{\mathrm{s}}\left[\mathrm{L} \mathrm{T}^{-1}\right]$, for both stage 1 sodic water infiltration $\left(t_{\mathrm{s}}^{*}\right.$ and $K_{\mathrm{s}}^{*}$, respectively) and stage 2 deionised water infiltration $\left(t_{\mathrm{s}}^{* *}\right.$ and $K_{\mathrm{s}}^{* *}$, respectively). Hydraulic conductivity was determined using Darcy's law in the form,

$K_{\mathrm{s}}=Q_{\mathrm{s}} /[(\Delta H / L) A]$,

where $K_{\mathrm{s}}\left[\mathrm{L} \mathrm{T}^{-1}\right]$ is saturated hydraulic conductivity, $Q_{\mathrm{s}}\left[\mathrm{L}^{3} \mathrm{~T}^{-1}\right]$ is the measured steady flow rate through the core, $\Delta H[\mathrm{~L}]$ is the difference in hydraulic head across the core, $L[\mathrm{~L}]$ is core length, and $A\left[\mathrm{~L}^{2}\right]$ is the cross-sectional area of the core. Specifics on apparatus and procedures can be found in Iovino (1997).

\subsection{Pressure infiltrometer measurements}

Twelve pressure infiltrometer (PI) measurements were conducted in the sandy loam soil, and 21 measurements in the clay soil. The PI consisted of a Mariotte reservoir $(0.11 \mathrm{~m}$ internal diameter $\times 1.20 \mathrm{~m}$ high) sealed to a stainless steel ring of radius, $a=0.075$ $\mathrm{m}$, which was driven to a depth, $d=0.05 \mathrm{~m}$, into the soil surface (Ciollaro and Lamaddalena, 1998). Within each ring, a thin layer of soil was scraped off the soil surface to remove any possible crusted/smeared/ compacted layer, and a filter cloth was laid down to minimize soil disturbance when the ring was flooded at the start of the measurement. Varying potential for reduction in hydraulic conductivity was achieved by applying a two-stage sodic water-deionised water infiltration procedure similar to that used for the soil core measurements. Stage 1 infiltration consisted of using the PI to infiltrate $11 \mathrm{~L}$ of sodic water with $\mathrm{SAR}=0,10,20$ or 30 , but fixed cationic strength of 10 cmol $\mathrm{kg}^{-1}$. Stage 2 infiltration, which followed immediately after stage 1 , consisted of using the PI to displace the previously infiltrated sodic water by infiltrating an additional $11 \mathrm{~L}$ of deionised water. A steady depth of ponding, $H=0.055 \mathrm{~m}$, was used for the sandy loam soil, while $H=0.11 \mathrm{~m}$ was used for the clay soil. Ponding was maintained in the PI ring during the switch-over from stage 1 infiltration (sodic water) to stage 2 infiltration (deionised water), as recommended in Reynolds (1993) and Reynolds and 
Elrick (2002). The time required to achieve steady flow, $t_{\mathrm{s}}[\mathrm{T}]$, was determined for both stage 1 infiltration $\left(t_{\mathrm{s}}^{*}\right)$ and stage 2 infiltration $\left(t_{\mathrm{s}}^{* *}\right)$ using the "cumulative drop" procedure of Bagarello et al. (1999).

Field-saturated hydraulic conductivity for both stage 1 infiltration, $K_{\mathrm{fs}}^{*}\left[\mathrm{~L} \mathrm{~T}^{-1}\right]$, and stage 2 infiltration, $K_{\mathrm{fs}}^{* *}\left[\mathrm{~L}^{-1}\right]$, was determined using (Reynolds, 1993; Reynolds and Elrick, 2002),

$K_{\mathrm{fs}}=\frac{G Q_{\mathrm{s}}}{G \pi a^{2}+a\left(H+\alpha^{*-1}\right)}$

where $K_{\mathrm{fs}}\left[\mathrm{L} \mathrm{T}^{-1}\right]$ is field-saturated hydraulic conductivity, $G$ is a dimensionless shape parameter given by,

$G=0.316 \frac{d}{a}+0.184$,

$Q_{\mathrm{s}}\left[\mathrm{L}^{3} \mathrm{~T}^{-1}\right]$ is steady flow rate out of the PI and into the soil, and $\alpha^{*}\left(\mathrm{~L}^{-1}\right)$ is a soil texture/structure parameter which was set to $\alpha^{*}=36 \mathrm{~m}^{-1}$ for the sandy loam and $\alpha^{*}=12 \mathrm{~m}^{-1}$ for the clay (Reynolds and Elrick, 2002). Further detail on the PI apparatus and procedures can be found in Reynolds (1993) and Reynolds and Elrick (2002). For each of the four SAR levels, three PI measurements were taken in the sandy loam soil, and four to six measurements were taken in the clay soil.

\subsection{Calculations and statistical analyses}

To better illustrate the impacts of sodicity on soil hydraulic conductivity, the ratio of deionised water hydraulic conductivity to sodic water hydraulic conductivity was calculated to obtain, $R_{\mathrm{SC}}=K_{\mathrm{S}}^{* *} / K_{\mathrm{S}}^{*}$ and $R_{\mathrm{PI}}=K_{\mathrm{fs}}^{* *} / K_{\mathrm{fs}}^{*}$, where $R_{\mathrm{SC}}$ refers to the laboratorybased soil core measurements and $R_{\mathrm{PI}}$ refers to the field-based pressure infiltrometer measurements. These $R$ values, the sodic water conductivity values $\left(K_{\mathrm{s}}^{*}, K_{\mathrm{fs}}^{*}\right)$, the stage 1 times to steady flow $\left(t_{\mathrm{s}}^{*}\right)$, and the stage 2 times to steady flow $\left(t_{\mathrm{s}}^{* *}\right)$ were plotted against SAR level, and linear regressions calculated to determine if relationships existed. The "strength" of the relationships was determined by calculating the coefficient of determination $\left(r_{\text {SAR }}^{2}\right)$ and its statistical significance.

Statistical comparisons between means (i.e., EC, ESP, SAR, $\left.t_{\mathrm{s}}, K_{\mathrm{s}}, K_{\mathrm{fs}}, R_{\mathrm{PI}}, R_{\mathrm{SC}}\right)$ were conducted using either the two-tailed $t$-test ( 2 means) or the Tukey "Honestly Significant Difference" test ( $\geq 3$ means) (Daniel, 1995). All statistical tests on $K_{\mathrm{fs}}$ or $K_{\mathrm{s}}$ were carried out using the natural logs of the data, as the statistical frequency distributions of the $K$ data were log-normal, which is usual for this soil property (Warrick and Nielsen, 1980). The other parameters (EC, ESP, SAR, $t_{\mathrm{s}}, R_{\mathrm{PI}}, R_{\mathrm{SC}}$ ) were assumed normally distributed, and thus, no transformations were performed on these data before statistical analysis. The probability level, $P=0.05$, was used for all statistical comparisons.

\section{Results}

\subsection{Soil core equilibration}

After stage 1 infiltration (sodic water), the SARs of the soil core solutions were similar to the corresponding equilibration solution SARs, regardless of whether IS or NIS procedures were used (Table 2); i.e., for equilibrating solution $\mathrm{SAR}=0$, the soil core SARs were 1.09 (IS) and 1.29 (NIS), and

\section{Table 2}

Arithmetic mean (AM) and coefficient of variation (CV) for electrical conductivity (EC), exchangeable sodium percentage (ESP) and sodium adsorption ratio (SAR) after stage 1 infiltration (sodic solution) or stage 2 infiltration (deionised water) for intact soil cores that had been previously saturated with equilibrating solution (IS) or not previously saturated with equilibrating solution (NIS)

\begin{tabular}{|c|c|c|c|c|c|c|c|}
\hline \multirow{2}{*}{$\begin{array}{l}\text { Equilibrating } \\
\text { Solution } \\
\text { SAR }\end{array}$} & \multirow{2}{*}{$\begin{array}{l}\text { Equilibration } \\
\text { procedure }\end{array}$} & \multicolumn{2}{|c|}{$\mathrm{EC}\left(\mathrm{dS} \mathrm{m} \mathrm{m}^{-1}\right)$} & \multicolumn{2}{|c|}{ ESP $(\%)$} & \multicolumn{2}{|l|}{ SAR } \\
\hline & & $\mathrm{AM}$ & $\begin{array}{l}\mathrm{CV} \\
(\%)\end{array}$ & $\mathrm{AM}$ & $\begin{array}{l}\mathrm{CV} \\
(\%)\end{array}$ & $\mathrm{AM}$ & $\begin{array}{l}\mathrm{CV} \\
(\%)\end{array}$ \\
\hline \multicolumn{8}{|c|}{ After stage 1 infiltration } \\
\hline \multirow[t]{2}{*}{0} & IS & $2.53 \mathrm{a}^{\mathrm{a}}$ & 47.8 & $8.39 \mathrm{a}$ & 13.7 & $1.09 \mathrm{a}$ & 15.9 \\
\hline & NIS & $1.36 \mathrm{a}$ & 27.1 & $9.43 \mathrm{a}$ & 10.5 & $1.29 \mathrm{a}$ & 3.8 \\
\hline \multirow[t]{2}{*}{30} & IS & $2.78 \mathrm{a}$ & 49.9 & $46.1 \mathrm{a}$ & 9.0 & $30.8 \mathrm{a}$ & 17.0 \\
\hline & NIS & $2.20 \mathrm{a}$ & 45.0 & $45.4 \mathrm{a}$ & 4.1 & $30.1 \mathrm{a}$ & 27.4 \\
\hline \multicolumn{8}{|c|}{ After stage 2 infiltration } \\
\hline \multirow[t]{2}{*}{0} & IS & $0.18 \mathrm{a}$ & 40.0 & $6.00 \mathrm{a}$ & 17.0 & $0.56 \mathrm{a}$ & 41.2 \\
\hline & NIS & $0.30 \mathrm{a}$ & 60.3 & $5.98 \mathrm{a}$ & 17.4 & $0.72 \mathrm{a}$ & 57.2 \\
\hline \multirow[t]{2}{*}{30} & IS & $0.65 \mathrm{a}$ & 43.6 & $32.5 \mathrm{a}$ & 5.9 & $12.1 \mathrm{a}$ & 41.0 \\
\hline & NIS & $0.51 \mathrm{a}$ & 70.7 & $30.8 \mathrm{a}$ & 5.3 & $7.12 \mathrm{a}$ & 99.1 \\
\hline
\end{tabular}

${ }^{\mathrm{a}}$ For a given SAR level $(0,30)$ and infiltration stage (Stage 1, Stage 2), means within a column followed by the same letter are not significantly different at $P<0.05$ according to a two-tailed $t$-test. 
for equilibrating solution $\mathrm{SAR}=30$, the soil core SARs were 30.8 (IS) and 30.1 (NIS). After stage 2 infiltration (deionised water), the EC, ESP and SAR levels of the soil cores dropped substantially (relative to their stage 1 values) for both IS and NIS equilibrated cores (Table 2). In addition, the EC, ESP and SAR levels of the soil cores were not significantly different $(P<0.05)$ between the IS and NIS procedures within each infiltration stage and equilibrating solution SAR (Table 2).

\subsection{Hydraulic conductivity measurements}

\subsubsection{Sandy loam soil}

Both infiltration stages of the field-based PI measurements (i.e., stage 1 infiltration of sodic water followed by stage 2 infiltration of deionised water) produced cumulative volume vs. time curves with an initial transient phase followed by a steady state phase. The transient phase was quite variable, however, and the time required to achieve steady flow ranged from virtually zero (Fig. 2a) to over $150 \mathrm{~min}$ (Fig. 2b). The correlation between time to steady flow $\left(t_{\mathrm{s}}\right)$ and SAR level was not significant for stage 1 infiltration $\left(r_{\mathrm{SAR}}^{2}=0.1296\right)$, but it was significant (although low) for stage 2 infiltration $\left(r_{\mathrm{SAR}}^{2}=0.2903\right)$ (Table 3). Plots of infiltration rate vs. time usually showed a decline in infiltration rate to a steady value for stage 1 infiltration, then a second decline in infiltration rate to a second steady value for stage 2 infiltration. The latter decline tended to increase from minimal for $S A R=0$ (Fig. 3a), to substantial for $\mathrm{SAR}=30$ (Fig. 3b).

A significant negative slope linear regression was obtained between the $R_{\mathrm{PI}}$ values and the corresponding SAR of the stage 1 infiltration solution (Fig. 4a, Table 4). Also, the mean $R_{\mathrm{PI}}$ ratio at each SAR differed according to the sequence $\mu\left(R_{\mathrm{PI}}\right)_{\mathrm{SAR}=0}>$ $\mu\left(R_{\mathrm{PI}}\right)_{\mathrm{SAR}=10}=\mu\left(R_{\mathrm{PI}}\right)_{\mathrm{SAR}=20}>\mu\left(R_{\mathrm{PI}}\right)_{\mathrm{SAR}=30}$ (Table 4$)$. This occurred because the mean reduction in $K_{\mathrm{fs}}^{* *}$ changed from an inconsequential minimum of 3\% for $\mathrm{SAR}=0$, to a substantial maximum of $85 \%$ for $\mathrm{SAR}=30$. No significant correlation was found, however, between the $K_{\mathrm{fs}}^{*}$ values and the SAR level (Table 3).

As with the PI measurements, the intact soil cores also produced a significant correlation between time to steady flow and SAR level for stage 2 infiltration of

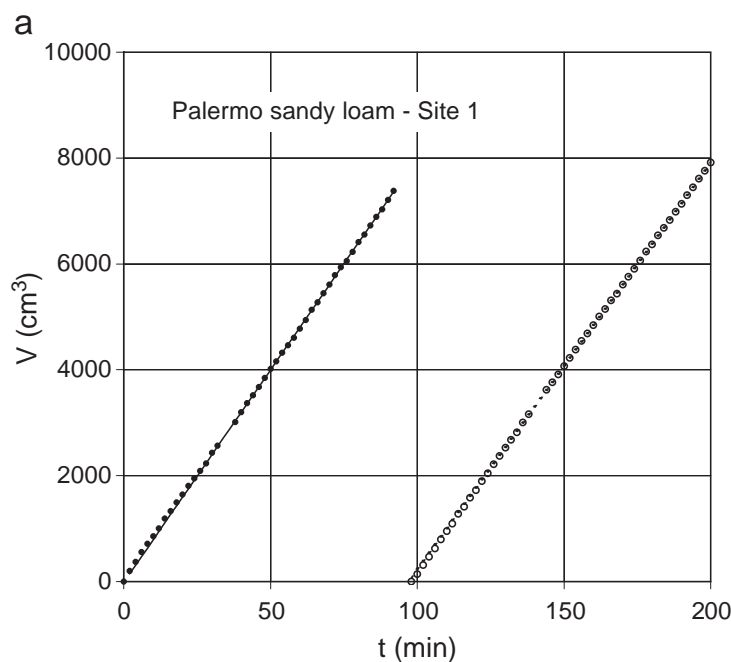

b

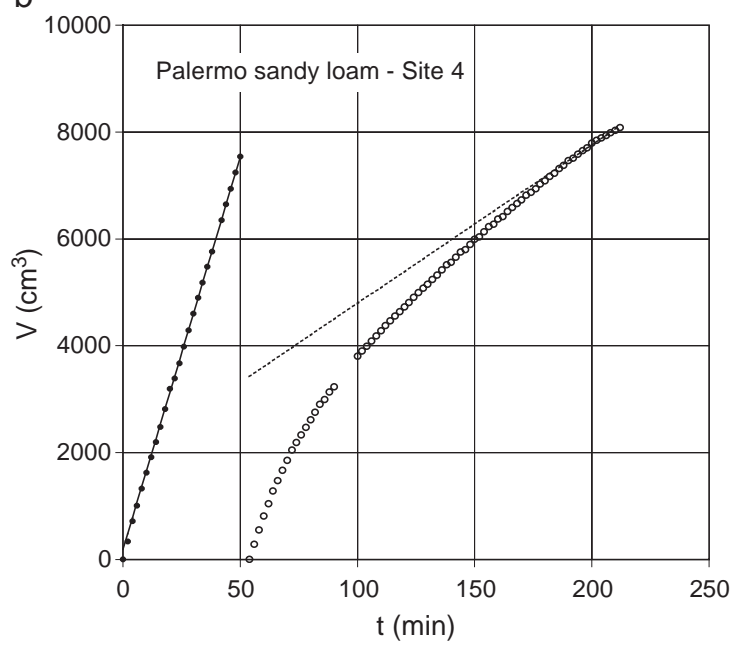

Fig. 2. Pressure infiltrometer measurements of cumulative infiltration volume $(V)$ vs. time $(t)$ in the sandy loam for stage 1 sodic water infiltration (solid circles) and stage 2 deionised water infiltration (open circles): (a) $\mathrm{SAR}=0$ for stage 1 solution; (b) $\mathrm{SAR}=30$ for stage 1 solution. The solid and broken lines are regressions based on the "cumulative drop" procedure of Bagarello et al. (1999).

deionised water, but not for stage 1 infiltration of sodic water (Table 3). Also, no significant correlation was found between $K_{\mathrm{s}}^{*}$ and the SAR level (Table 3). The mean $K_{\mathrm{s}}^{*}$ obtained from the intact soil cores was not significantly different from the mean $K_{\text {fs }}^{*}$ obtained from the in situ PI measurements, although the core values had a slightly greater $\mathrm{CV}$ which probably reflects the smaller sample size (Table 3 ). The 
Table 3

Sample size $(n)$, arithmetic mean (AM), geometric mean (GM), and coefficient of variation (CV) for stage 1 time to steady flow $\left(t_{\mathrm{s}}^{*}\right)$, stage 2 time to steady flow $\left(t_{\mathrm{s}}^{* *}\right)$, stage 1 saturated hydraulic conductivity $\left(K_{\mathrm{s}}^{*}\right)$, and stage 1 field-saturated hydraulic conductivity $\left(K_{\mathrm{fs}}^{*}\right)$

\begin{tabular}{|c|c|c|c|c|c|c|c|c|c|c|c|}
\hline \multirow[t]{2}{*}{ Soil type } & \multirow[t]{2}{*}{ Method $^{\mathrm{a}}$} & \multirow[t]{2}{*}{$n$} & \multicolumn{3}{|c|}{$\mathrm{t}_{\mathrm{s}}^{*}(\min )$} & \multicolumn{3}{|c|}{$t_{\mathrm{s}}^{* *}(\min )$} & \multicolumn{3}{|c|}{$K_{\mathrm{fs}}^{*}$ or $K_{\mathrm{s}}^{*}\left(\mathrm{~mm} \mathrm{~h}^{-1}\right)$} \\
\hline & & & $\mathrm{AM}$ & CV $(\%)$ & $r_{\mathrm{SAR}}^{2}$ & $\mathrm{AM}$ & CV $(\%)$ & $r_{\mathrm{SAR}}^{2}$ & GM & $\mathrm{CV}(\%)$ & $r_{\mathrm{SAR}}^{2}$ \\
\hline \multirow[t]{2}{*}{ Sandy loam } & PI & 12 & 51.7 & 159.1 & $0.1296^{\mathrm{b}}$ & 136.2 & 203.4 & $0.2903^{\mathrm{c}}$ & $182.0 \mathrm{a}^{\mathrm{d}}$ & 77.8 & $0.0820^{\mathrm{b}}$ \\
\hline & $\mathrm{SC}$ & 9 & 83.9 & 98.0 & $0.3051^{\mathrm{b}}$ & 618.3 & 162.1 & $0.4563^{\mathrm{c}}$ & $91.5 \mathrm{a}$ & 98.0 & $0.0066^{\mathrm{b}}$ \\
\hline \multirow[t]{2}{*}{ Clay } & PI & $16^{\mathrm{e}}$ & 66.5 & 91.5 & $0.0209^{\mathrm{b}}$ & 106.9 & 88.8 & $0.0387^{\mathrm{b}}$ & $91.9 \mathrm{a}$ & 335.7 & $0.0402^{\mathrm{b}}$ \\
\hline & $\mathrm{SC}$ & 11 & 1073.2 & 170.4 & $0.5882^{\mathrm{c}}$ & 1369.5 & 139.7 & $0.5684^{\mathrm{c}}$ & $19.7 \mathrm{a}$ & 483.5 & $0.6061^{\mathrm{c}}$ \\
\hline
\end{tabular}

The coefficients of determination $\left(r_{\mathrm{SAR}}^{2}\right)$ for linear regression of $t_{\mathrm{s}}^{*}, t_{\mathrm{S}}^{* *}, K_{\mathrm{fs}}^{*}$ and $K_{\mathrm{S}}^{*}$ against stage 1 SAR level are also given.

${ }^{\text {a }} \mathrm{PI}=$ in situ pressure infiltrometer; $\mathrm{SC}=$ intact laboratory soil core.

b Correlation coefficient $(r)$ not significantly greater than zero at $P<0.05$.

c Correlation coefficient $(r)$ significantly greater than zero at $P<0.05$.

${ }^{\mathrm{d}}$ For a given soil type, values within the GM column followed by the same letter are not significantly different at $P<0.05$.

${ }^{\mathrm{e}} n=15$ for $t_{\mathrm{s}}^{*}$ and $t_{\mathrm{s}}^{* *} ; n=16$ for $K_{\mathrm{fs}}^{*}$ and $K_{\mathrm{s}}^{*}$.

reduction in $R_{\mathrm{SC}}$ with increasing $\mathrm{SAR}$ followed the same pattern as that for $R_{\mathrm{PI}}$, ranging from a minimal reduction for $\mathrm{SAR}=0(\approx 8 \%)$ to a substantial reduction for $\mathrm{SAR}=30(\approx 94 \%)$ (Table 4$)$. The mean $R_{\mathrm{SC}}$ ratio followed the sequence $\mu\left(R_{\mathrm{SC}}\right)_{\mathrm{SAR}=0}=$ $\mu\left(R_{\mathrm{SC}}\right)_{\mathrm{SAR}=10}>\mu\left(R_{\mathrm{SC}}\right)_{\mathrm{SAR}=20}=\mu\left(R_{\mathrm{SC}}\right)_{\mathrm{SAR}=30} \quad$ (Table $4)$. A significant negative linear correlation was obtained between $R_{\mathrm{SC}}$ and SAR (Fig. $4 \mathrm{~b}$ ), and this relationship did not differ significantly from the $R_{\mathrm{PI}}$ vs. SAR relationship obtained for the PI method (Table 4).

No suspended clay was observed in core effluent during infiltration of sodic water (as expected), but suspended clay did appear in the effluent during infiltration of deionised water. The amount of migrating suspended clay was too small to be measured at $\mathrm{SAR}=0$, but for greater SAR levels the suspended clay content ranged from a high of $4.9-5.1 \mathrm{~g} \mathrm{~L}^{-1}$ during early-time infiltration of deionised water to a low of near zero at later times.

\subsubsection{Clay soil}

Five of the 21 PI measurements were not successful in the clay because of an excessively high flow rate into the soil (the PI reservoirs emptied within $<2 \mathrm{~min}$ ). This was likely due to rapid flow through shrinkage cracks, which were evident on the soil surface at the time of the PI measurements (late spring). Occasional rapid flow through shrinkage cracks or macropores coupled with much slower flow through the soil matrix when no cracks were intercepted would also explain the large CVs obtained for both $K_{\mathrm{fs}}{ }^{*}$ and $K_{\mathrm{s}}{ }^{*}$ (Table 3).
For the PI measurements in the clay soil, no significant correlations were obtained for $t_{\mathrm{S}}^{*}$ vs. $\mathrm{SAR}, t_{\mathrm{s}}^{* *}$ vs. SAR, $K_{\mathrm{fs}}^{*}$ vs. SAR, and $R_{\mathrm{PI}}$ vs. SAR (Tables 3 and 4 ). However, $R_{\mathrm{PI}}$ tended to decrease with increasing SAR level (Fig. 5a) and the mean $R_{\mathrm{PI}}$ value at $\mathrm{SAR}=30\left[\mu\left(R_{\mathrm{PI}}\right)_{\mathrm{SAR}=30}\right]$ was statistically smaller than the mean $R_{\mathrm{PI}}$ value at $\mathrm{SAR}=0$ $\left[\mu\left(R_{\mathrm{PI}}\right)_{\mathrm{SAR}=0}\right]$ according to a one-tailed $t$-test. The SC measurements, on the other hand, produced significant correlations in the clay soil for $t_{\mathrm{s}}^{*}$ vs. SAR, $t_{\mathrm{s}}^{* *}$ vs. SAR, and $K_{\mathrm{s}}^{*}$ vs. SAR (Table 3 ). A significant negative correlation also occurred between $\ln \left(R_{\mathrm{SC}}\right)$ vs. SAR (Fig. 5b, Table 4 ), and mean $R_{\mathrm{SC}}$ followed the sequence $\mu\left(R_{\mathrm{SC}}\right)_{\mathrm{SAR}=0}>\mu$ $\left(R_{\mathrm{SC}}\right)_{\mathrm{SAR}=10}=\mu\left(R_{\mathrm{SC}}\right)_{\mathrm{SAR}=20}=\mu\left(R_{\mathrm{SC}}\right)_{\mathrm{SAR}=30} \quad$ (Table 4). In addition, the mean $K_{\mathrm{S}}{ }^{*}$ from the $\mathrm{SC}$ method was not significantly different from the mean $K_{\mathrm{fs}}^{*}$ from the PI (Table 3). The amount of suspended clay migrating from the clay soil cores ranged from 0.41 $\mathrm{g} \mathrm{L}^{-1}$ effluent (for $\mathrm{SAR}=0$ ) to $6.34 \mathrm{~g} \mathrm{~L}^{-1}$ effluent (for $\mathrm{SAR}=30$ ) at the start of deionised water infiltration, but dropped to negligible levels after elution of about 4 pore volumes.

\section{Discussion}

The soil core equilibration results (Table 2) indicate that quasi-equilibrium between the soil and the infiltrating solution was attained within the intact soil cores, and that prior saturation and equilibration (IS procedure) did not significantly $(P<0.05)$ enhance chemical equilibrium relative to no prior saturation 
a

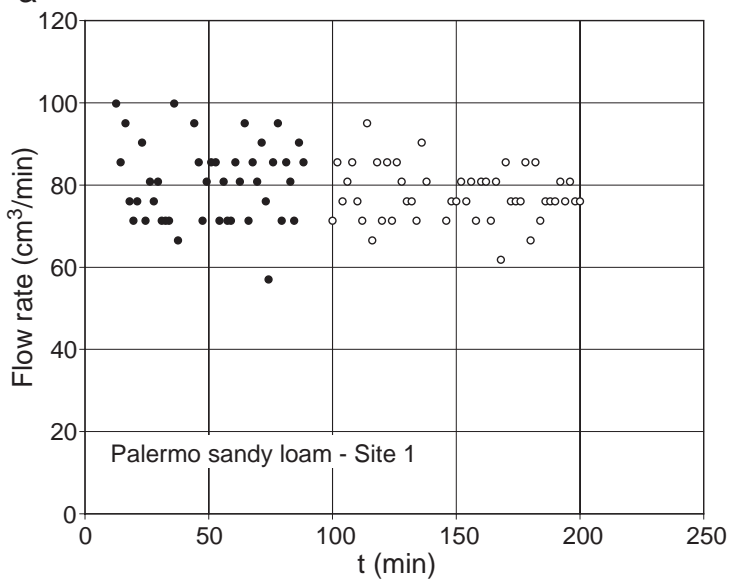

b

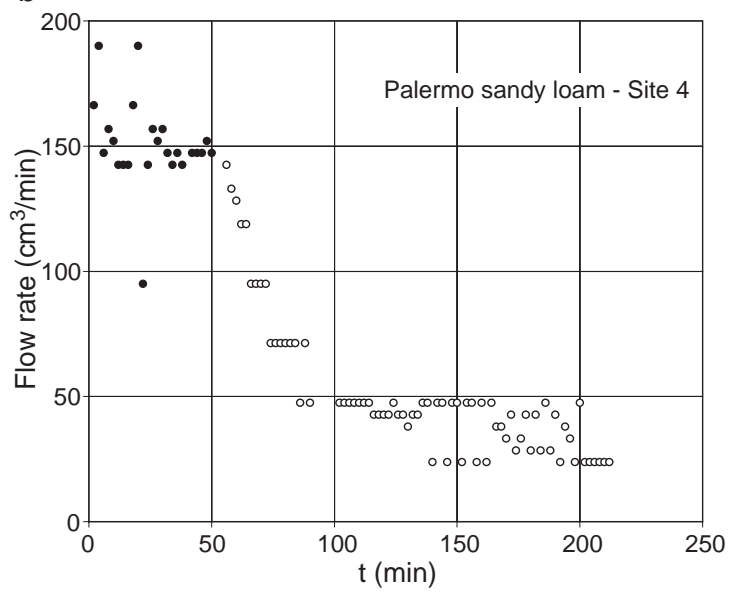

Fig. 3. Pressure infiltrometer measurements of infiltration (flow) rate vs. time $(t)$ in the sandy loam soil for stage 1 sodic water infiltration (solid circles) and stage 2 deionised water infiltration (open circles): (a) $\mathrm{SAR}=0$ for stage 1 solution; (b) $\mathrm{SAR}=30$ for stage 1 solution.

and equilibration (NIS procedure). As a consequence, quasi-equilibrium in the soil during stage 1 and stage 2 infiltration should have also occurred during the laboratory and field measurements of hydraulic conductivity.

For the PI measurements, the initial decline (early-time transient) in infiltration rate during sodic water (stage 1) infiltration (e.g., Fig. 3a and b) is an expected consequence of wetting initially unsaturated soil (Elrick and Reynolds, 1992). The eventual attainment of steady flow during stage 1 infiltration indicates constant field-saturated hydraulic conductivity $\left(K_{\mathrm{fs}}^{*}\right)$ in the saturated soil within the PI ring, which in turn implies stable soil during sodic water infiltration. The stage 2 earlytime transients, on the other hand, indicate that changes occurred in the soil during deionised water infiltration (such as aggregate slaking and clay dispersion) which caused $K_{\mathrm{fs}}$ to decline (e.g., Fig. $3 b)$.

The general lack of correlation between SAR and $t_{\mathrm{s}}^{*}, K_{\mathrm{s}}^{*}$ or $K_{\mathrm{fs}}^{* *}$ (Table 3) indicates that the SAR level of the sodic water equilibrating solution (stage 1 infiltration) had no appreciable effect on the infiltration process, saturated hydraulic conductivity, or fieldsaturated hydraulic conductivity of the soils tested.
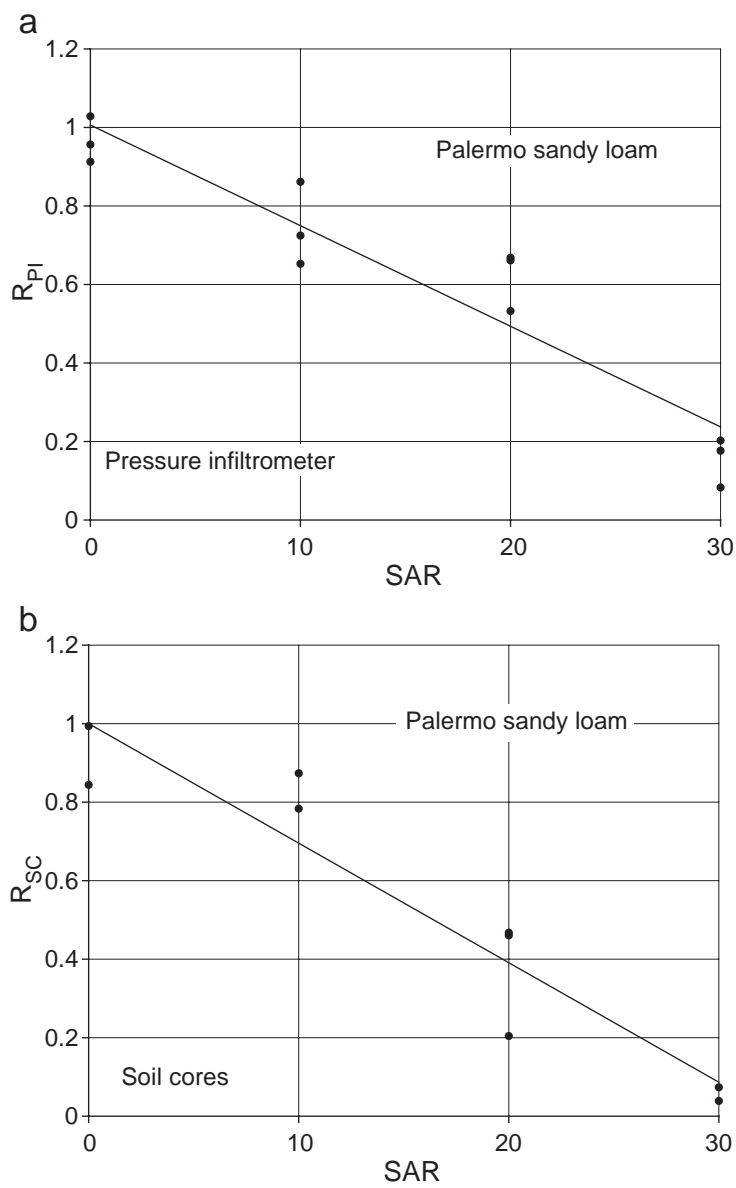

Fig. 4. Hydraulic conductivity ratio, $R$, vs. stage 1 SAR for the sandy loam soil at Palermo: (a) field-based pressure infiltrometer, $R_{\mathrm{PI}}$; (b) laboratory-based cores of intact soil, $R_{\mathrm{SC}}$. The solid lines are regressions with parameter values (intercept, slope, $r_{\mathrm{SAR}}^{2}$ ) given in Table 4. 
Table 4

Effect of sodium adsorption ratio, $\mathrm{SAR}$, on hydraulic conductivity ratio, $R_{\mathrm{PI}}$ or $R_{\mathrm{SC}}$

\begin{tabular}{|c|c|c|c|c|c|c|c|c|c|}
\hline \multirow[t]{2}{*}{ Soil type } & \multirow[t]{2}{*}{ Method $^{\mathrm{a}}$} & \multirow[t]{2}{*}{ Statistic } & \multicolumn{4}{|c|}{ SAR of stage 1 infiltration solution } & \multicolumn{3}{|c|}{$R_{\mathrm{PI}}$ or $R_{\mathrm{SC}}$ vs. SAR regression } \\
\hline & & & 0 & 10 & 20 & 30 & Intercept & Slope & $r_{\mathrm{SAR}}^{2}$ \\
\hline \multirow[t]{6}{*}{ Sandy Loam } & PI & $n$ & 3 & 3 & 3 & 3 & $1.0060^{\mathrm{b}}$ & $-0.0256^{\mathrm{c}}$ & $0.8888^{\mathrm{d}}$ \\
\hline & & Mean $R$ & $0.966 \mathrm{a}^{\mathrm{e}}$ & $0.746 \mathrm{~b}$ & $0.621 \mathrm{~b}$ & $0.154 \mathrm{c}$ & & & \\
\hline & & CV $(\%)$ & 6.1 & 14.2 & 12.3 & 40.8 & & & \\
\hline & $\mathrm{SC}$ & $n$ & 2 & 2 & 3 & 2 & $1.0004^{\mathrm{b}}$ & $-0.0305^{\mathrm{c}}$ & $0.8949^{\mathrm{d}}$ \\
\hline & & Mean $R$ & $0.919 \mathrm{a}$ & $0.828 \mathrm{a}$ & $0.377 \mathrm{~b}$ & $0.056 \mathrm{~b}$ & & & \\
\hline & & CV $(\%)$ & 11.5 & 7.7 & 39.6 & 43.5 & & & \\
\hline \multirow[t]{6}{*}{ Clay } & PI & $n$ & 3 & 5 & 3 & 5 & 0.7677 & -0.0086 & $0.1518^{\mathrm{f}}$ \\
\hline & & Mean $R$ & $0.907 \mathrm{a}$ & $0.588 \mathrm{a}$ & $0.491 \mathrm{a}$ & $0.583 \mathrm{a}$ & & & \\
\hline & & CV (\%) & 37.9 & 29.7 & 67.6 & 23.1 & & & \\
\hline & $\mathrm{SC}$ & $n$ & 3 & 3 & 3 & 2 & $-0.5120^{\mathrm{g}}$ & $-0.1896^{\mathrm{g}}$ & $0.6361^{\mathrm{d}, \mathrm{g}}$ \\
\hline & & Mean $R$ & $0.869 \mathrm{a}$ & $0.120 \mathrm{~b}$ & $0.038 b$ & $0.017 \mathrm{~b}$ & & & \\
\hline & & CV (\%) & 27.8 & 116.4 & 164.9 & 136.5 & & & \\
\hline
\end{tabular}

Statistics include sample size $(n)$, mean $R$ value (Mean $R$ ) and coefficient of variation of $R(\mathrm{CV})$. Also included are the regression parameters (intercept, slope, $r_{\mathrm{SAR}}^{2}$ ) for the $R_{\mathrm{PI}} \mathrm{Vs}$. SAR and $R_{\mathrm{SC}}$ Vs. SAR regressions.

${ }^{\mathrm{a}} \mathrm{PI}=$ pressure infiltrometer; $\mathrm{SC}=$ laboratory soil core.

b Not significantly different from unity at $P<0.05$.

${ }^{c}$ PI and SC slopes not significantly different at $P<0.05$.

${ }^{d}$ Correlation coefficient $(r)$ significantly different from zero at $P<0.05$.

e Means within a row followed by the same letter are not significantly different at $P<0.05$.

${ }^{\mathrm{f}}$ Correlation coefficient $(r)$ not significantly different from zero at $P<0.05$.

${ }^{g}$ Regression of $\ln \left(R_{\mathrm{SC}}\right)$ vs. SAR.

This implies in turn that the various SAR levels did not cause appreciable clay dispersion or changes in soil structure, despite the fact that the initial SAR of the soil solution was low (Table 1). Supporting this is the fact that during sodic water infiltration (stage 1), no appreciable suspended clay appeared in core effluent, and steady state infiltration was attained in the field-based PI measurements.

For the sandy loam soil, the positive correlations between SAR vs. $t_{\mathrm{s}}^{* *}$ (Table 3 ), and the negative correlations between SAR vs. $R_{\mathrm{PI}}$ and $R_{\mathrm{SC}}$ (Table 4; Fig. 4), indicate that the infiltration of deionised water (stage 2 infiltration) was affected by the SAR of the sodic equilibrating water (stage 1 infiltration). Supporting this is the fact that stage 2 steady infiltration rates in the field-based PI measurements tended to decrease with increasing SAR of the sodic equilibrating water (Fig. 3). The appearance of suspended clay in the soil core effluent during elution with deionised water further implies that the changes in $t_{\mathrm{s}}^{* *}, K_{\mathrm{s}}^{* *}$ and $K_{\mathrm{fs}}^{* *}$ were due to aggregate slaking and/or partial plugging of soil pores by clay particles that became dispersed and mobile after contact with the deionised water. The statistical equivalence of the $R_{\mathrm{PI}}$ vs. SAR and $R_{\mathrm{SC}}$ vs. SAR relationships (Table 4) suggests that the PI method was both effective and equivalent to the intact SC method for characterizing the impacts of sodicity on the saturated hydraulic conductivity of that soil.

In the clay soil, lack of correlation between SAR vs. $t_{\mathrm{s}}^{* *}$ and SAR vs. $R_{\mathrm{PI}}$ from the in situ PI measurements (Tables 3 and 4) probably indicates that flow occurred primarily within the network of shrinkage cracks, and not within the massive soil matrix. Suspended clay particles are less likely to block relatively large and smooth shrinkage cracks than small, tortuous matrix pores. On the other hand, the appearance of suspended clay in the soil core effluent, and the strong correlations between SAR vs. $t_{\mathrm{S}}^{* *}$ and SAR vs. $R_{\mathrm{SC}}$ (Tables 3 and 4), probably occurred because the soil cores were maintained in a saturated state for $96 \mathrm{~h}$ prior to stage 1 and stage 2 infiltration. This would encourage soil cracks and other large pores to swell partially closed, thus making the cracks more susceptible to partial blockage by suspended clay particles. Although the shrinkage cracks probably introduced strong vertical-horizontal anisotropy in flow patterns and hydraulic parameters, 
a

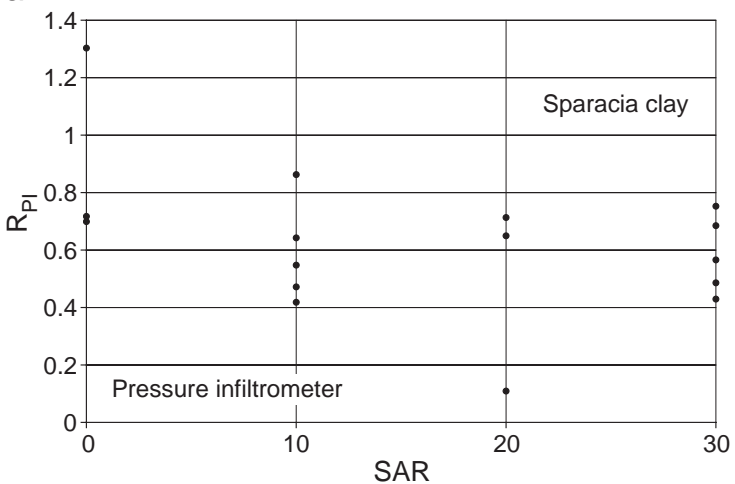

b

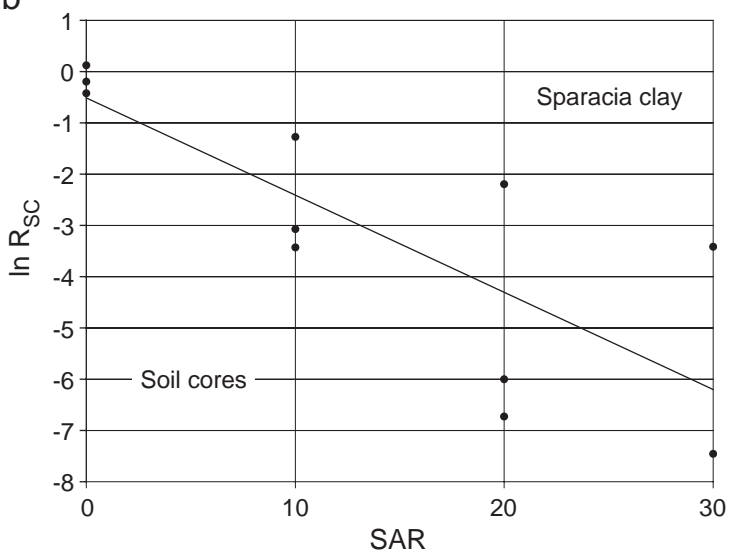

Fig. 5. Hydraulic conductivity ratio, $R$, vs. stage $1 \mathrm{SAR}$ for the clay soil at Sparacia: (a) field-based pressure infiltrometer, $R_{\mathrm{PI}}$; (b) laboratory-based cores of intact soil, $R_{\mathrm{SC}}$. The solid line is a regression with parameter values (intercept, slope, $r_{\mathrm{SAR}}^{2}$ ) given in Table 4.

it is very unlikely that anisotropy contributed to the observed discrepancies between the PI and SC results, as both methods produce confined vertical flow throughout the saturated soil volume (Reynolds, 1993).

The mean times to steady flow for stage 2 (deionised water) infiltration $\left(t_{\mathrm{s}}^{* *}\right)$ through the PI tended to be short $(107-136 \mathrm{~min})$ relative to the corresponding times for the SC (618-1370 min) (Table 3). This suggests that in situ reductions in soil $K_{\mathrm{fs}}$ as a result of aggregate slaking and clay dispersion/mobilization can occur relatively soon after the introduction of water with lower cationic concentration than the resident soil water. The field-based PI method may therefore be particularly useful for characterizing the time scale of sodicity effects on saturated soil hydraulic conductivity.

The above results exemplify how the intact SC method and the in situ PI method complement and enhance the traditional repacked core approach. Repacked cores of sieved soil are obviously incapable of detecting the shrinkage crack and time scale effects found by the SC and PI. Moreover, the additional "intact soil" information provided by the SC and PI methods may prove essential for improved understanding and control of sodicity.

\section{Conclusions}

Quasi-equilibrium between soil and infiltrating solution was attained in small laboratory cores $(0.08$ $\mathrm{m}$ diameter by $0.05 \mathrm{~m}$ long) of intact (undisturbed) soil regardless of whether or not the cores were previously saturated and equilibrated with sodic solution over a 96-h time period. This implies as a consequence that quasi-equilibrium between soil and infiltrating solution should have also occurred during the laboratory and field measurements of hydraulic conductivity.

In the non-cracking sandy loam soil, the fieldbased pressure infiltrometer method was statistically equivalent to laboratory cores of intact soil for characterizing sodicity-induced reductions in hydraulic conductivity. In the cracking clay soil, the pressure infiltrometer results suggested that shrinkage cracks may mitigate early-time sodicity-induced reductions in hydraulic conductivity, while the intact core results suggested that later-time sodicity effects combined with swelling-induced closure of cracks can cause substantial reductions in hydraulic conductivity. In both soils, the time required to achieve steady flow during stage 2 (deionised water) infiltration was substantially shorter for the pressure infiltrometer method than for the intact soil core method. Given that the traditional repacked laboratory core approach would not have detected these potentially important behaviours, we conclude that the pressure infiltrometer and intact core methods are useful complements to the traditional approach for characterizing the reduction in soil hydraulic conductivity as a result of dilution of sodic soil water with rainfall or lowsodium irrigation water. 
Dilution of sodic soil water $(\mathrm{SAR}=0,10,20$ or 30$)$ by deionised water caused the saturated and/or fieldsaturated hydraulic conductivity to decrease in a saltaffected sandy loam soil and a salt-affected clay soil in western Sicily. The decrease in hydraulic conductivity ranged from 3-8\% (initial soil water $\mathrm{SAR}=0$ ) to 85 $94 \%$ (initial soil water $\mathrm{SAR}=30$ ) in the sandy loam, and from $9-13 \%(\mathrm{SAR}=0)$ to $42-98 \%(\mathrm{SAR}=30)$ in the clay. The decrease appeared to be the result of swelling, aggregate slaking and partial blocking of water-conducting pores by clay particles that had become dispersed and mobilized by the infiltrating deionised water. As a result, long-term maintenance of hydraulic conductivity in these salt-affected soils will likely require procedures to control the build-up of sodicity.

\section{Acknowledgements}

V. Bagarello, M. Iovino and W.D. Reynolds designed the experiments; V. Bagarello and M. Iovino conducted the hydraulic conductivity measurements; and E. Palazzolo and M. Panno carried out the chemical analyses. All authors contributed to data analysis and writing of the manuscript. Funding for this research was provided by Università degli Studi di Palermo and Ministero dell'Istruzione, dell'Università e della Ricerca of Italy.

\section{References}

Abu-Sharar, T.M., Bingham, F.T., Rhoades, J.D., 1987. Reduction in hydraulic conductivity in relation to clay dispersion and disaggregation. Soil Sci. Soc. Am. J. 51, 342-346.

Agassi, M., Morin, J., Shainberg, I., 1985. The effect of water drop impact energy and water salinity on the infiltration rates of sodic soils. Soil Sci. Soc. Am. J. 49, 186-190.

Bagarello, V., Iovino, M., Reynolds, W.D., 1999. Measuring hydraulic conductivity in a cracking clay soil using the Guelph Permeameter. Trans. ASAE 42 (4), 957-964.

Ben-Hur, M., Agassi, M., Keren, R., Zhang, J., 1998. Compaction, aging, and raindrop-impact effects on hydraulic properties of saline and sodic vertisols. Soil Sci. Soc. Am. J. 62, 1377-1383.

Bohn, H.L., McNeal, B.L., O'Connor, G.A., 1979. Soil Chemistry. John Wiley and Sons, Toronto.

Ciollaro, G., Lamaddalena, N., 1998. Effect of tillage on the hydraulic properties of a vertic soil. J. Agric. Eng. Res. 71, $147-155$.
Crescimanno, G., Iovino, M., Provenzano, G., 1995. Influence of salinity and sodicity on soil structural and hydraulic characteristics. Soil Sci. Soc. Am. J. 59, 1701-1708.

Daniel, W.W., 1995. Biostatistics: A Foundation for Analysis in the Health Science. John Wiley and Sons, Hobochen, NJ.

Elrick, D.E., Reynolds, W.D., 1992. Infiltration from constant-head well permeameters and infiltrometers. In: Topp, G.C., Reynolds, W.D., Green, R.E. (Eds.), Advances in Measurement of Soil Physical Properties: Bringing Theory into Practice, SSSA Spec. Publ., vol. 30. Soil Sci. Soc. Am., Inc, Madison, WI, pp. 1-24.

Food and Agriculture Organization of the United Nations, 1998. World reference base for soil resources. 84 World Soil Resources Reports. International Society of Soil Science, International Soil Reference and International Centre. Roma, Italy.

Frenkel, H., Goortzen, J.O., Rhoades, J.D., 1978. Effects of clay type and content, exchangeable sodium percentage and electrolyte concentration on clay dispersion and soil hydraulic conductivity. Soil Sci. Soc. Am. J. 42, 32-39.

Hausenbuiller, R.L., 1978. Soil Science: Principles and Practices. Wm.C. Brown Company Publishers, Dubuque, IA.

Iovino, M., 1997. Effetti della composizione chimica delle acque di irrigazione sulla conducibilità idrica satura del terreno agrario. Riv. Ing. Agrar. 2, 105-116 (in Italian with English abstract).

Mamedov, A.I., Shainberg, I., Levy, G.J., 2002. Wetting rate and sodicity effects on interrill erosion from semi-arid Israeli soils. Soil Tillage Res. 68, 121-132.

Minhas, P.S., Naresh, R.K., Chauhan, C.P.S., Gupta, R.K., 1994. Field determined hydraulic properties of a sandy loam soil irrigated with various salinity and SAR waters. Agric. Water Manag. 25, 97-108.

Ministero delle Politiche Agricole e Forestali, 2000. Metodi di Analisi Chimica del Suolo. Franco Angeli, Milano, Italy.

Moutier, M., Shainberg, I., Levy, G.J., 1998. Hydraulic gradient, aging, and water quality effects on hydraulic conductivity of a vertisol. Soil Sci. Soc. Am. J. 62, 1488-1496.

Reynolds, W.D., 1993. Saturated hydraulic conductivity: field measurement. In: Carter, M.R. (Ed.), Soil Sampling and Methods of Analysis. Canadian Society of Soil Science. Lewis Publishers, Boca Raton, FL, pp. 599-613.

Reynolds, W.D., Elrick, D.E., 1990. Ponded infiltration from a single ring: I. Analysis of steady flow. Soil Sci. Soc. Am. J. 54, $1233-1241$.

Reynolds, W.D., Elrick, D.E., 2002. Pressure infiltrometer. In: Dane, J.H., Topp, G.C. (Eds.), Methods of Soil Analysis: Part 4. Physical methods. Soil Sci. Soc. Am., Inc., Madison, WI, pp. $826-836$.

Rhoades, J.D., Loveday, J., 1990. Salinity in irrigated agriculture. In: Stewart, B.A., Nielsen, D.R. (Eds.), Irrigation of Agricultural Crops, Agronomy, vol. 30. Soil Sci. Soc. Am. Inc., Madison, WI, pp. $1089-1142$.

Shainberg, I., Warrington, D., Laflen, J.M., 1992. Soil dispersibility, rain properties, and slope interaction in rill formation and erosion. Soil Sci. Soc. Am. J. 56, 278-283.

So, H.B., Aylmore, L.A.G., 1993. How do sodic soils behave? The effects of sodicity on soil physical behavior. Aust. J. Soil Res. 31, 761-777. 
Sumner, M.E., 1993. Sodic soils: new perspectives. Aust. J. Soil Res. 31, 683-750.

USDA (United States Department of Agriculture), 1998. Keys to Soil Taxonomy. 8th ed.

Warrick, A.W., Nielsen, D.R., 1980. Spatial variability of soil physical properties in the field. In: Hillel, D. (Ed.),
Applications of Soil Physics. Academic Press, New York, NY, pp. 319-344.

Yousaf, M., Ali, O.M., Rhoades, J.D., 1987. Clay dispersion and hydraulic conductivity of some salt-affected arid land soils. Soil Sci. Soc. Am. J. 51, 905-907. 